This is an Accepted Manuscript (AM) of an article published by Elsevier in Transportation Research Part F: Traffic Psychology and Behaviour on 10/04/2019, available online: https://doi.org/10.1016/j.trf.2019.03.019

To cite the paper please use the published version:

Huertas-Leyva, P., Nugent, M., Savino, G., Pierini, M., Baldanzini, N., \& Rosalie, S. (2019). Emergency braking performance of motorcycle riders: Skill identification in a real-life perception-action task designed for training purposes. Transportation research part F: traffic psychology and behaviour, 63, 93-107. doi.org/10.1016/j.trf.2019.03.019

(C2019 Elsevier. This manuscript version is made available under the CC-BY-NC-ND 4.0 license http://creativecommons.org/licenses/by-nc-nd/4.0/ after the 24 month embargo period provided that all the terms and conditions of the licence are adhered to.

\title{
Emergency braking performance of motorcycle riders: skill identification in a real-life perception-action task designed for training purposes
}

\author{
P. Huertas-Leyva, M. Nugent, G. Savino, M. Pierini, N. Baldanzini, S. Rosalie \\ Dipartimento di Ingegneria Industriale, Università degli Studi di Firenze, Via di Santa Marta 3, 50139 Firenze, Italy
}

${ }^{*}$ Corresponding author at: Università degli Studi di Firenze, Department of Mechanics and Industrial Technologies, Via di Santa Marta 3, 50139 Firenze, Italy e-mail: pedro.huertasleyva@unifi.it

\begin{abstract}
Collisions with other vehicles represent the biggest threat to riders of powered-two-wheeler (PTW), and while emergency braking is the evasive manoeuvre most frequently required in PTW riding, many riders fail to perform it adequately due to constraints on response time precipitated by failures of perception, cognition and control actions. Effective rider training methods are necessary for the development of braking proficiency in response to emergency situations.

This study proposes a testing and training paradigm that exploits a closer similitude with the real-world scenario by maintaining the natural coupling of action (vehicle manoeuvring) and perception (higher order skill) that underlies any coordinated response to an emergency event. The aim of this study was to understand the behaviour of the riders in the execution of emergency braking coupled with visual perception of vehicle motion as a response to an imminent collision and determine parameters that can be used to identify differences in skill level.

Participants performed emergency braking trials in a realistic and controlled scenario using a mock-up of an intersection conflict with a real car initiating a left turn manoeuvre across the path of a PTW approaching from the opposite direction (Left Turn Across Path/Opposite Directions). Analysis of the deceleration patterns recorded during 12 trials per participant revealed that performance of braking in response to an unpredicted moving hazard differs from that in a planned self-timed hard braking. In addition, our results indicate that PTW rider performance may be assessed in a reliable and objective way using the combination of vehicle kinematics and human performance measures. The study identified four categories of riders classified by their level skills. Finally, an important finding was the lack of correlation of both years of riding experience and self-assessed overall riding skill with an objective measure of emergency braking performance such as effective deceleration. The results of this study will support a new training approach and provide insights for future design of active safety systems.
\end{abstract}

Keywords

Motorcyclist Safety; braking performance; Rider behaviour; Rider training; Perception-action response 


\section{INTRODUCTION}

Riders of powered two wheelers (PTW), are exposed to significantly higher accident and injury risk compared to drivers of four-wheeled vehicles, due to their inherent lower stability and higher vulnerability. Collisions with other vehicles represent the biggest threat to PTW riders. Emergency braking is the evasive manoeuvre most frequently required in PTW riding (Penumaka, Savino, Baldanzini, \& Pierini, 2014), and has also been reported as the most difficult manoeuvre to learn (Dewar, Rupp, Gentzler, \& Mouloua, 2013). In fact, many riders fail to perform it adequately due to constraints on response time precipitated by failures of perception, cognition and control actions (Penumaka et al., 2014; Sporner \& Kramlich, 2001). This is a complex perceptual motor task that requires timely application of properly proportioned front and rear brake pressure, in proper correspondence with variations in road friction and vehicle stability. Effective rider training methods are necessary for the development of adequate braking proficiency in response to emergency situations. A review of current literature assessing the effectiveness of training on crash avoidance shows conflicting results across studies. Some authors have reported that motorcycle riders with training have fewer crashes on average than untrained riders (Billheimer, 1998; Davis, 1997), while other authors found no differences in crash rates (Ivers et al., 2016; Jonah, Dawson, \& Bragg, 1982; Mortimer, 1988), or even higher crash rates for riders with training (António \& Matos, 2008; Savolainen \& Mannering, 2007). Two reviews of past studies of training programs (Daniello et al., 2009; Kardamanidis, Martiniuk, Ivers, Stevenson, \& Thistlethwaite, 2010) found that many had important methodological limitations (poor control groups, small sample sizes, self-report data) leading to inconclusive results, while in other studies, the lack of exposure data casts doubt on the reliability of the results. Nevertheless, the lack of evidence of the effectiveness of training programs for crash reductions does not necessarily point to the inefficacy of training to improve safety. Elliott et al. (2003) highlighted some possible reasons for the lack of effectiveness of training, including the possibility that skills are not being properly translated into on-road riding and that skills related to crash involvement are not clearly identified and not properly trained. In a review on hazard perception training, Wallace, Haworth, \& Regan (2005) pointed out that during formal training in a risk-free environment, the hazardous conditions actually presented are very limited. Riders need realworld conditions to become fully skilled. Nevertheless, in most cases training and license tests are carried out in unrealistic and predictable environments (Aupetit, Riff, Buttelli, \& Espié, 2013), relying on exercises that artificially separate control skill actions and hazard perception, not sufficient to assess the ability to ride safely in traffic (OECD/ITF, 2015). The challenge, then, is to develop the training tasks that will enable novice riders to accelerate their mastery of the skills required in crash scenarios (Collins, Mulvihill, \& Symmons, 2012).

From the literature it may be argued that there is a limited knowledge about which PTW crash scenarios are the most relevant when specific riding skills like braking are required. In-depth studies of PTW crashes showed that the failure of other road user to perceive the motorcyclists in time to avoid the crash is the most prevalent crash contributing factor (ACEM, 2009; Hurt, Ouellet, \& Thom, 1981), reported in most instances by a failure to give right of way to the motorcyclists at intersections (Clarke, Ward, Bartle, \& Truman, 2007). The scenario of an opponent car initiating an unexpected left turn across the path of a PTW (Left Turn Across Path/Opposite Directions - LTAP/OD), was identified as the most frequent PTW scenario among crashes with severe injuries or fatalities (Huertas-Leyva, 2018); furthermore, in most of those cases the rider response was to brake or non-evasive action.

Previous studies related to braking with PTWs have: defined the theoretical optimum braking manoeuvre (Corno, Matteo, Tanelli, \& Fabbri, 2008; Cossalter, Lot, \& Maggio, 2004); evaluated the capabilities of different braking systems through tests performed by one to three riders executing a self-initiated braking when reaching a signalized stopping area (Anderson \& Baxter, 2010; Dinges \& Hoover, 2018; Dunn et al., 2012); assessed the potential benefits of motorcycle autonomous emergency braking (Savino, Giovannini, Baldanzini, Pierini, \& Rizzi, 2013); and demonstrated the feasibility 
of identifying behavioural riding patterns in real traffic (Attal, Boubezoul, Oukhellou, \& Espié, 2015; Baldanzini, Huertas-Leyva, Savino, \& Pierini, 2016). Only a few studies have assessed the braking performance of riders (by measuring the braking deceleration rate) either executing self-initiated braking upon passing a set of traffic cones (Vavryn \& Winkelbauer, 2004) or braking after the onset of a static red light (Davoodi \& Hamid, 2013; Ecker, Wassermann, Hauer, Ruspekhofer, \& Grill, 2001; Prem, 1987). Additionally, the relationship between braking performance and rider experience, explored in two of the previous studies (Ecker et al., 2001; Vavryn \& Winkelbauer, 2004), showed discrepant conclusions. PTW rider training needs skill measurement methods (Savolainen \& Mannering, 2007) and research to better understand riders behaviour in emergency scenarios. However, there are no existing studies that have assessed riding skills using motorcycle dynamics measurements in a realistic hazard scenario.

We propose a more appropriate skill testing/training paradigm that exploits a closer similitude with the real-world scenario by maintaining the natural coupling of perception (higher order skill) and action (vehicle manoeuvring) inherent in any coordinated response to an emergency event. The aim of this study was threefold. First, to test whether a real-world emergency braking task could be used to examine PTW riders' ability to avoid a collision by rapidly decelerating. To achieve this, we created a controlled LTAP/OD scenario that required riders to predict whether a car would turn across their path and to respond by braking in the shortest distance possible. Second, to determine whether performance in the task could be used to categorize riders in terms of skill in emergency braking. Third, to examine how skill in emergency braking correlates with riders' self-reported experience and self-assessed expertise in terms of overall, safety, traffic hazard perception and emergency braking skills. Specifically, we hypothesized that (1) braking acceleration profiles would show different groupings of skill level, where higher skilled riders would be identifiable by higher deceleration rates. Additionally, we predicted that (2) the rider performance braking in the task designed for this study differs from the standard self-determined braking initiation task. We further hypothesized that (3) neither amount of experience, nor selfassessed overall skill and safety, nor self-assessed skill in perceiving traffic hazards and braking are correlated with actual emergency braking ability.

\section{METHODOLOGY}

\subsection{Participants}

Thirteen subjects (11 male, 2 female) aged 23 to 47 years (mean 32.3; SD 8.9), having various levels of expertise were recruited by contacting riding schools and local racetracks, reaching out to groups through social media and posting flyers at the University of Florence. Candidates were screened by questionnaire to determine if they met the selection criteria. All participants were required to have held a motorcycle license with no engine size limitation for more than 3 months, to have their own PTW and to ride regularly (minimum once per week). Demographic data collected from the questionnaire included: gender, age, motorcycle riding experience in years and kilometres and information on training courses and track experience. In addition, self-characterization with respect to overall skills riding and skills related to safety, hazard perception and braking were collected. Approval was granted by an institutional human research ethics committee to recruit licensed PTW riders of varying skill levels in order to investigate the relationship between experience and skill in emergency braking using the protocol described below. All participants gave their informed written consent to participate in the experiment.

\subsection{Equipment and data collection}

Small-to-medium sized scooters $(150-300 \mathrm{cc})$ represent the type of PTW most frequently sold in Italy. For this reason, the experimental PTW used was a 300cc Piaggio Beverly scooter with automatic power transmission and standard brakes independently actuated - no anti-lock braking system (ABS) or combined braking system (CBS) - by two hand levers 
(right-front and left-rear). The scooter was instrumented with an array of sensors connected to an on-board data acquisition system to record the dynamics of the vehicle (Figure 1).
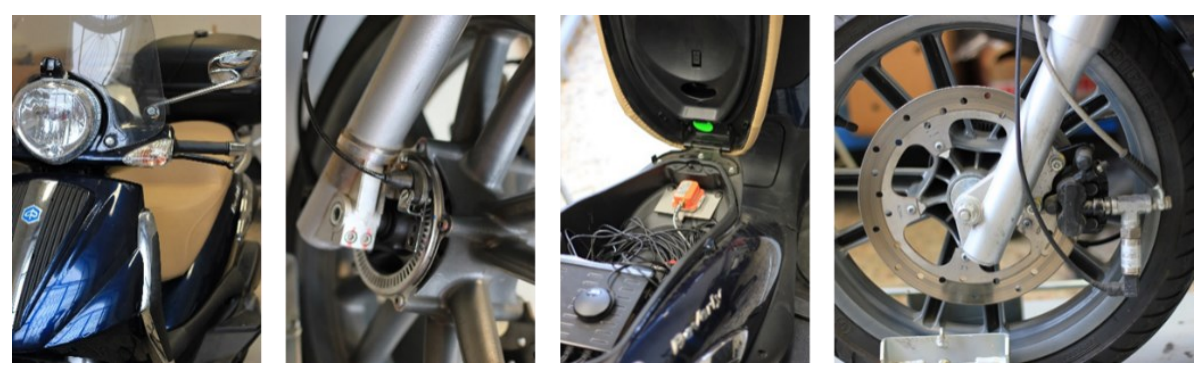

Figure 1. Scooter 300cc instrumented

An X-Sens inertial measurement unit (IMU) with an integrated GPS was used to record vehicle triaxial acceleration, pitch, roll and yaw angles, plus position and speed. The speed of each wheel was measured separately using phonic wheels, read as incremental encoder signals. Steering angle and throttle position were measured using a rotational transducer and an angular sensor, respectively, each having a range of $120^{\circ}$ and an accuracy of $0.3^{\circ}$. Brake usage was acquired redundantly from two different types of sensors: braking intensity was acquired from pressure transducers attached to front and rear brake circuits separately; brake activation was monitored from the touch of the brake levers acquired directly from the electrical wiring for each lever. All signals were sampled at a rate of $100 \mathrm{~Hz}$. In addition to vehicle measurements, the rider's muscle activity and body segment accelerations were recorded using Delsys Trigno ${ }^{\mathrm{TM}}$ IM wireless wearable sensors with integrated surface electromyography (EMG) electrodes and triaxial IMUs. Muscle onsets, rider dynamics and activity patterns will be used to characterize rider control behaviour and performance in future studies and have not been analysed here.

The timing and sources of visual information that guides emergency braking was examined using two high-speed video cameras (GoPro Hero5 Black) set at sampling rates of $100 \mathrm{fps}$ to record environmental events and rider actions. The camera recording environmental events was placed on the front of the scooter to capture the exact onset of car turn initiation. The second camera was mounted facing the rider to record head movements, primarily. In addition, a tripodmounted video camera was placed adjacent to the experimental "intersection" to record the lateral view of the encounter between the two vehicles during each trial. An LED activated by a clock signal from the data logger was mounted in the field of view for each camera for later offline synchronization of the video data with the vehicle data recorded by the DAQ system. Figure 2 shows an example of a video frame with signals from instrumentation overlaid.
1. Front Brake Pressure (bars)
2. Rear Brake Pressure (bars)
3. Speed $(\mathrm{km} / \mathrm{h})$
4. Steering angle (deg)
5. Throttle position (deg)
6. Velocity time series (trial)
7. LED for synchronization

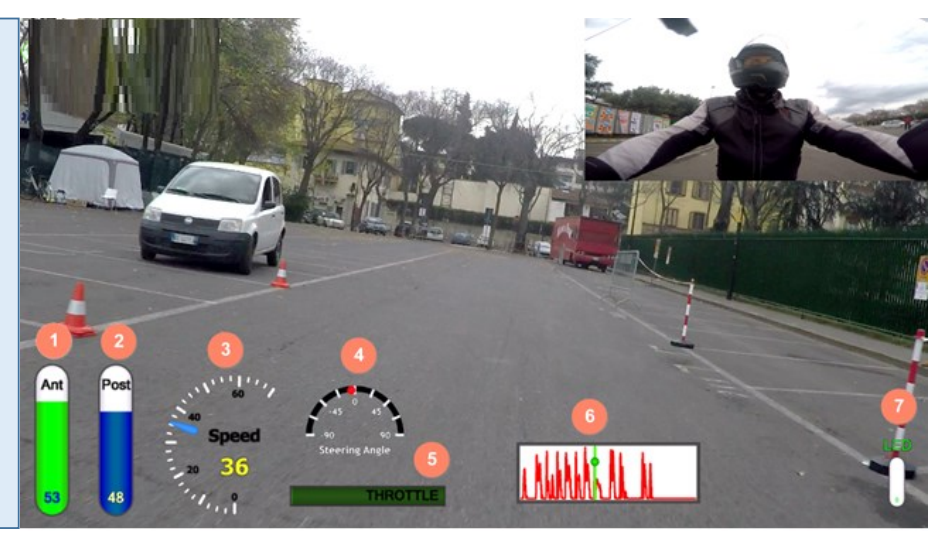

Figure 2. Representation of a videoed trial overlaid with signals from instrumented scooter. 


\subsection{Experimental Procedure}

Data collection occurred in two asphalt parking lots located in metropolitan Florence. In each parking lot, a testing area measuring $90 \mathrm{~m}$ x 20m was barricaded off using municipal traffic barriers to prevent the entry of the regular pedestrian and vehicular traffic. Paved asphalt was in good condition and the vehicle was equipped with standard high grip tires to guarantee maximum adherence. All tests were carried out in daylight and in dry conditions. The experimental trials consisted of a series of emergency braking tests using an opponent vehicle (passenger car) in a stimulus-response time paradigm, followed by a set of self-initiated hard braking trials with no hazard stimulus, i.e. no other vehicle or external action cue (see Table 1).

Table 1. Description of the test phases during the experimental procedure

\begin{tabular}{|c|c|c|}
\hline Protocol Phases & Time/Trials & Description \\
\hline Pre-Test Phase & $\geq 10 \mathrm{~min}$ & Environment and PTW Familiarization \\
\hline Emergency braking tests: Practice trials & 7 trials & One or two repetitions per condition $\mathrm{TN}, \mathrm{TI}, \mathrm{SN}, \mathrm{SI}$ \\
\hline Emergency braking tests with car: $1^{\text {st }}$ set & 8 trials & Six repetitions per each condition (24 trials): \\
\hline Emergency braking tests with car: $2^{\text {nd }}$ set & 8 trials & $\begin{array}{ll}\text { TN - car Turns with No indicator } & \text { (brake event) } \\
\text { TI - car Turns with Indicator } & \text { (brake event) }\end{array}$ \\
\hline Emergency braking tests with car: $3^{\text {rd }}$ set & 8 trials & $\begin{array}{l}\text { SN - car goes Straight with No indicator } \\
\text { SI - car goes Straight with Indicator }\end{array}$ \\
\hline Emergency braking test: Additional trials & $0-4$ trials & $\begin{array}{l}\text { Additional trials added to the } 3^{\text {rd }} \text { set in case some trial } \\
\text { was not performed following the prescribed condition. }\end{array}$ \\
\hline Self-initiated hard braking tests & 3 trials & $\begin{array}{l}\text { Hard braking when reaching a virtual line delimited by } \\
\text { cones (no opponent vehicle) }\end{array}$ \\
\hline
\end{tabular}

\subsubsection{Emergency braking test at an intersection}

A mock intersection was demarcated using existing curbs and lane markings, with the addition of poles and traffic cones, in order to create an experimental scenario that closely mimicked a non-controlled intersection typical of the Florence road network. Figure 3a provides a schematic view of the mock intersection, orientated such that a car approaching from one end could either continue straight through the intersection or make a left turn.

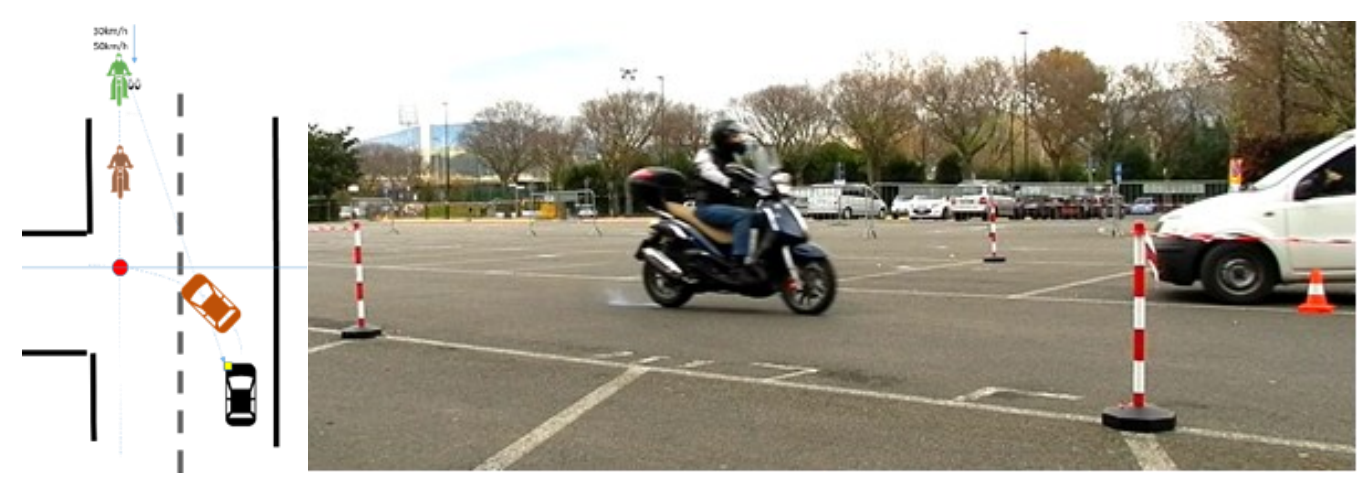

Figure 3. a) Schematic view of the mock intersection; b) Trial with car initiating a LTAP/OD manoeuvre

The experiment required participants to visually perceive the movement and indicator signals of a car approaching the intersection from the opposite direction, and carry out an appropriate response. In each trial the car approached the intersection at a speed of $30 \mathrm{~km} / \mathrm{h}$. The car either continued straight through the intersection or initiated a left turn that would cross the path of the scooter ridden by the participant. Both scenarios were performed either with or without turn signal prior to entering the intersection. Each of these four conditions was repeated six times for a total of 24 trials, which were presented in three blocks of eight trials. The four conditions were pseudo-randomized and counterbalanced so that for each trial the rider had an equal chance of having to respond appropriately to the car which either: turned left with noindicator (TN), turned after indicating (TI), continued straight on with no indicator ( $\mathrm{SN}$ ), or continued straight on despite 
indicating a left turn (SI). During the experimental sessions each participant had to perform a minimum of 12 emergency braking trials.

Before commencing the experimental trials, participants were asked to ride through the mock intersection and practice braking for a minimum of 10 minutes in order to familiarize themselves with both the experimental scooter and the testing environment ${ }^{1}$. Following this self-guided warmup period, participants were provided with seven practice trials that demonstrated the four conditions mentioned above. For the first four practice trials, participants were informed of the manoeuvre that the car would execute and whether the turn signal would be activated prior to the trial. In the last three trials, participants performed practice trials exactly as they would be presented in the experiment - without foreknowledge of the car's manoeuvres or indications.

For both the practice and experimental trials the vehicles started from stationary positions at opposite ends of the experimental area. For the PTW start position the rear wheel was placed on a chalk line measured at a distance $45 \mathrm{~m}$ from the nearest edge of the intersection. After a visual 'go' signal both vehicles began moving towards the intersection. Participants were instructed to reach speeds of $40-55 \mathrm{~km} / \mathrm{h}$ on approach to the intersection and respond according to whether the car turned or continued straight on. Specifically, participants were instructed to brake as quickly and as hard as possible while maintaining balance and control, as in an emergency situation, only if they perceived that the car would turn across their path, regardless of whether the turn indicator was active or not. On the contrary, participants were instructed to continue through the intersection if they perceived that the car would continue straight on, again regardless of whether the car had the turn indicator on. After each trial both vehicles returned to their initial positions to await the 'go' signal for the next trial.

To ensure the safety of the participant, the oncoming vehicle never completed the turn in front of the PTW, but stopped short of the center line in order to avoid any risk of collision with the rider (Figure 3b). The car was driven by one of the experimenters who practiced each manoeuvre during several pilot sessions as well as prior to each experimental session to ensure safe and consistent performance. An important element of the experimental procedure was the synchronization between the two vehicles, that is, the relative distance between them when the car initiated the turn at the intersection. Consistency across trials was ensured largely by the physical constraints of the test area and the target maximum velocities for both vehicles. With practice (on the part of the investigators on the ground, the car driver, and the participants during the familiarization trials) optimal timing for the participant to depart towards the intersection was achieved by choosing an instantaneous reference position relative to the car's travel in the test area (during practiced trials, the investigator coached the participant as to which timing cue to use from the car's path to achieve a realistic synchronization). In a given trial, if the driver executed the wrong condition according to the predetermined trial order, or the synchronization between the vehicles at the intersection was considered by one investigator to be too poor for the purposes of the experiment, the trial was repeated after the conclusion of the last sets of eight trials. The number of these repetitions ranged from $0-4$ additional trials.

\section{Braking Process}

In the scenario of an emergency braking as evasive manoeuvre, the braking process can be divided in two stages (see Figure 4). First stage is related to the response time, which is the time between the onset of the hazard and the start of the brake action on the PTW wheels. This stage includes on one side the time to perceive, recognize and make the decision

\footnotetext{
${ }^{1}$ Prior to familiarization, participants were instrumented with wireless electromyography sensors incorporating 9 DOF inertial measurement units; however, this data will not be reported here.
} 
(decision was minimized in our study since the riders were instructed to brake after hazard perception, to the exclusion of any other type of avoidance manoeuvre). On the other side it is the rider's movement time required to apply the brake action after the rider has decided to brake. The second stage is related to the complete braking action until the PTW has stopped. The work presented in this paper corresponds to this stage and concerns the braking control skills of the rider.

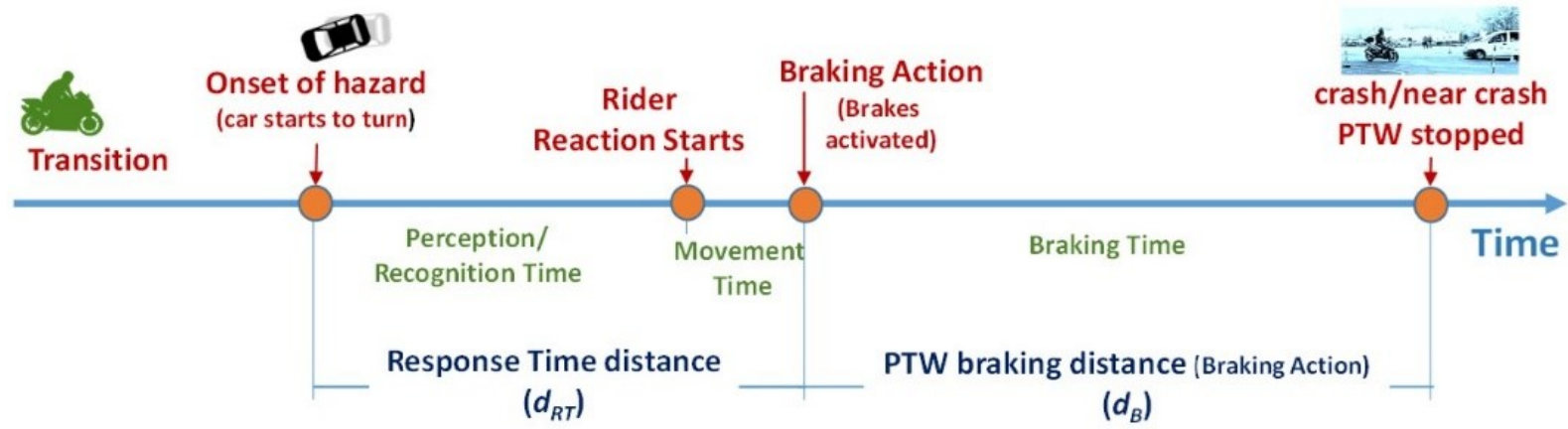

Figure 4. Components of braking process during emergency evasive manoeuvre.

\section{Time-To-Intersection}

The situational urgency, characterized by the initial state of the scenario, has been measured using the time to intersection (TTI). TTI was defined as the time it would take the PTW to reach the center of the intersection at the moment that the opposite car began to turn in front of the rider trajectory (if the PTW maintained its approach speed). TTI was computed using the PTW speed $(v)$ at the onset of the car turning in front of the PTW and using the PTW-intersection distance $\left(d_{P T W}\right.$ intersection) which was defined as the distance from PTW to the point estimated where the car turning trajectory would intersect with the PTW straight line trajectory (see equation 1).

$$
T T I=\frac{d_{P T W-\text { intersection }(\text { onset of car turning })}}{v \text { (onset of car turning) }}
$$

TTI of the trial was set to make the rider to perceive an inminent crash where only a combined high perception and braking performance could avoid the collision.

\subsubsection{Self-initiated Hard Braking with no opponent vehicle}

Following the emergency braking trials, participants performed three self-initiated hard braking manoeuvres with no opponent vehicle. The participants were instructed to reach $50 \mathrm{~km} / \mathrm{h}$ and then brake as hard as possible on arriving at a virtual line indicated by traffic cones placed on either side of the lane. The line was used merely as a reference and participants were not constrained to brake at that exact point since the braking distance was measured from the initial application of the brakes until the PTW stopped.

\subsection{Braking parameters as measures of braking performance}

The initiation of the braking period (Brake $i n i)$ was defined as the time at which the pressure applied to either the front or rear brake exceeded a threshold of 2 bars while longitudinal acceleration was negative. We identified 2 bars as the threshold indicating when the rider was using the brakes in an intended, purposeful manner to effect deceleration (in contrast to lower pressures that may have been anticipatory and did not effectively reduce wheel speed). The end of the braking period $\left(\right.$ Stop $\left._{P T W}\right)$ was defined as the time at which wheel speed dropped below $2 \mathrm{~km} / \mathrm{h}$ to avoid the inclusion of end-of-stop oscillations in speed. The differentiated signals were then filtered by Gaussian smoothing with a 0.2 seconds window. 
The braking distance $\left(d_{B}\right)$ was measured by integrating the PTW speed time series $v(t)$ during the braking period:

$$
d_{B}=\int_{\text {Brake }_{\text {ini }}}^{\text {Stop }} v(t) d t \underset{\text {, in discrete form becomes }}{n-1} d_{B}=\sum_{j=1}^{n} \frac{v_{j}}{T_{S}}
$$

where $n$ is the number of samples in the braking period, $T_{s}$ the sample rate ( 0.01 seconds) and $v_{j}$ is the PTW speed in the instant $j$.

Deceleration for the entire braking period was measured using both the IMU speed and the wheel speed. The longitudinal acceleration $\left(a_{\text {long }}\right)$ was computed from the differential of the speed data obtained from the wheel and the IMU during deceleration (4).

$$
a_{\text {long }}(t)=\frac{d}{d t} v(t)
$$

In discrete form (4) becomes

$$
a_{\text {long }}[n]=\frac{v_{n}-v_{n-1}}{T_{S}} \Rightarrow \operatorname{dec}_{\text {long }}[n]=-a_{\text {long }}[n]
$$

Peak deceleration $\left(\operatorname{dec}_{\text {peak }}\right)$ and effective deceleration ( $\left(\operatorname{dec}_{\text {effective }}\right)$ values were used to evaluate rider performance with comparisons across trials and subjects. The $d e c_{p e a k}$ was computed as the 95 th percentile of the longitudinal deceleration (dec long $)$ time series as a more robust value than the absolute maximum deceleration (which could be just a transient peak). The effective deceleration ( $\left(\operatorname{dec}_{\text {effective }}\right.$ ) was computed using the braking distance $\left(d_{B}\right)$ and the difference between final velocity at stop $\left(v_{f} \approx 2 \mathrm{~km} / \mathrm{h}\right.$ ) and velocity at braking initiation $\left(v_{i}\right)$ (equation 6 ). This measure provides an accurate assessment of the rider's actual braking performance in a given trial because it relates directly to total braking distance.

$$
\operatorname{dec}_{\text {effective }}=-\frac{\left(v_{f}^{2}-v_{i}^{2}\right)}{2 * d_{B}}
$$

Additionally, the initial jerk jerk $k_{\text {ini }}$ (deceleration gradient) defined as the average jerk between the start of the braking period $\left(\mathrm{T}_{1}\right)$ and the instant when the deceleration curve reaches $4.5 \mathrm{~m} / \mathrm{s}^{2}\left(\mathrm{~T}_{2}\right)$ was selected as a kinematic parameter of the braking pattern (equation 7). The value of $4.5 \mathrm{~m} / \mathrm{s}^{2}$ was selected to assure a maximum deceleration that all the participants could achieve during the first phase of braking, making possible the comparison of all the trials of the riders from the lowest to the highest braking competency.

$$
\operatorname{jerk}_{\text {ini }}=\frac{\operatorname{dec}_{\text {long }}\left[T_{2}\right]-\operatorname{dec}_{\text {long }}\left[T_{1}\right]}{T_{2}-T_{1}}=\frac{4.5 \mathrm{~m} / \mathrm{s}^{2}}{\Delta T}
$$

\subsection{Statistical Analyses}

\subsubsection{Categorization of different braking competencies}

To evaluate differences between subjects as a measure of skill, the effective and peak decelerations were first computed for each subject for all braking trials. To test the hypothesis that deceleration profile provides an objective measure of performance (and thus skill), we performed ANOVAs on effective deceleration $\left(\operatorname{dec}_{\text {effective }}\right.$ ) and peak deceleration ( $\left.\operatorname{dec}_{\text {peak }}\right)$ with subject as the factor, followed by a post-hoc Tukey analysis to determine groups that were significantly different from each other. In addition, the effect size (partial èta squared, $\eta_{p}{ }^{2}$ ) was also considered with $\eta_{p}{ }^{2}=.01$ as small, $\eta_{p}{ }^{2}=.06$ as medium, and $\eta_{p}{ }^{2}>.14$ as a large effect size (Cohen, 1988). 


\subsubsection{Effect of distracting component (turn indicator)}

The effect of the design of the scenario was studied comparing brake performance between the condition of car turn with indicator (TI) and turn without indicator (TN). The purpose was to determine whether there were differences between skill levels in the perception of the environment with a distracting visual stimulus component like turn indicator signal (car did not necessarily turn when the indicator was used). The effect of the turning condition (indicator/no indicator) was analysed by repeated measures ANOVA using the means of the $d e c_{e f f e c t i v e ~}$ by subject as dependent variable, computed separately for the each type of trial (TN and TI).

\subsubsection{Comparison of Hard braking and Emergency braking test}

The emergency task defined during this study was compared to a more standard hard braking exercise to assess whether the rider braking performance differed when initiation was self-determined compared to in response to a moving hazard stimulus. To balance the two samples and avoid bias because of learning effect or fatigue for this comparison the sample of the emergency braking trials corresponded to the three last braking trials of each participant. To test the hypothesis that braking in response to an unpredicted stimulus versus pre-planned braking differs in performance outcomes, we used a linear mixed-effects model including Type of test as fixed factor and crossed random effects for Trial order and Rider with random slope and intercepts (accounting for baseline differences between riders). The best fit model for each variable was defined by the number of parameters and the -2 Log likelihood values of the model.

\subsubsection{Braking performance vs years of Experience and skill Self-Assessment}

Spearman's rho tests were performed to test for a relationship between years of experience, self-assessed measures of skill and $d e c_{\text {effective }}$ as an objective braking performance indicator. The $95 \%$ confidence intervals for the correlations were calculated by transforming the correlation values to Fisher $Z$ statistics, then calculating the standard error and $95 \%$ confidence interval of the $\mathrm{Z}$ scores before transforming the upper and lower bounds for the $\mathrm{Z}$ tests back to the correlation coefficients (Altman, Machin, Bryant, \& Gardner, 2000).

\section{RESULTS}

\subsection{Emergency braking test at an intersection}

The data from the analysis of the PTW dynamics corresponds to 157 emergency braking trials performed by 13 riders. In the majority of these trials the participant performed braking when required according to the condition of the protocol, but in some instances (typically earlier in the test session) the rider did not perceive the car turning in time and continued through the intersection without braking. Consequently, for some subjects the number of usable braking events after the make-up trials was less than 12 , but no fewer than 10 braking trials. One exception was the least experienced rider with 7 braking trials done, who failed to brake on several trials and who was not asked to conduct additional trials to avoid overexertion.

\subsubsection{Time to Intersection (TTI)}

The TTI as indicator of the situational urgency represented in this task was calculated for 111 trials where the video quality allowed a frame by frame analysis to determine time of onset of car turning. The average TTI for all 13 riders was 1.22 seconds (SD 0.39), equivalent to a stopping distance required of 17 meters (including the response time distance) for a travelling speed of $50 \mathrm{~km} / \mathrm{h}$. The frequency distribution of the TTI of the trials is presented in Figure 5 . The ANOVA of TTI using subject as a factor revealed significant individual differences in TTI $\left(F(12,98)=3.17, p=.001, \eta_{p}{ }^{2}=.261\right)$. The source of these individual differences was broken down by descriptive analysis of the data which suggested that two test participants (identified as S08 and S11) were outliers in the range (means of 1.60 and 0.90 seconds respectively). A 
follow-up ANOVA for individual differences excluding these two participants subsequently revealed no significant difference in TTI $\left(F(10,80)=1.85, p=.065, \eta_{p}{ }^{2}=.178\right)$.

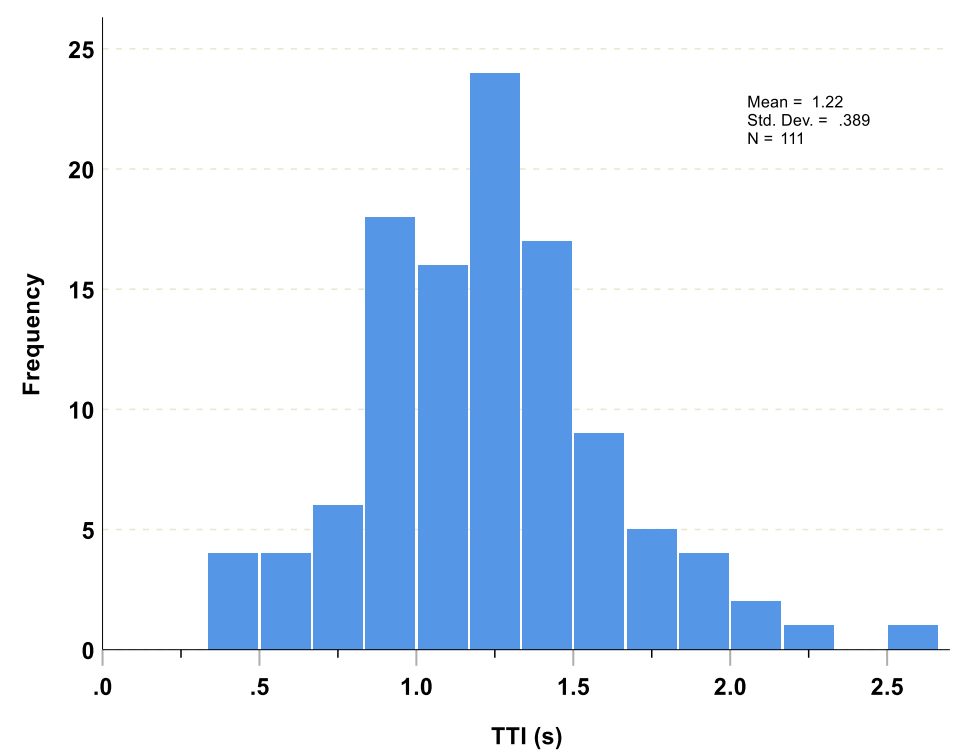

Figure 5. Histogram of TTI during the emergency braking test

\subsubsection{Skill differences in braking performance}

The results of the ANOVA on effective and peak deceleration revealed that there are significant differences in performance across riders ( dec $_{\text {effective: }} F(12,144)=36.63, p<.001, \eta_{p}{ }^{2}=.75$; dec $\left.c_{\text {peak }}: F(12,144)=87.66, p<.001, \eta_{p}{ }^{2}=.88\right)$. The Tukey's post-hoc tests (alpha set at 0.05) revealed four categories of riders differing significantly in effective and peak deceleration ( $d e c_{\text {effective }}$ and $\left.d e c_{\text {peak }}\right)$ that were composed by the same subjects in both variables. The categories were defined as 'A-Novice' (1 subject), 'B-Intermediate' (4 subjects), 'C-Advanced' (6 subjects) and 'D-Expert' (2 subjects). Table 2 lists the means and standard deviations (SD) for effective and peak deceleration for each category found. Category 'A-Novice' contains only the 7 trials of the novice rider as commented previously. It is important to note that standard deviation of the different skill categories in effective and peak deceleration is inversely proportional to skill with both standard deviations decreasing as skill level increases.

Table 2. Mean and standard deviation (SD) by skill level category for effective and peak deceleration.

\begin{tabular}{l|c|c|c|c|c|c} 
& & & \multicolumn{3}{c}{ Deceleration $\left(\mathrm{m} / \mathbf{s}^{2}\right)$} \\
\cline { 4 - 7 } Skill Level & $(\mathrm{N})$ & $(\mathrm{N})$ & \multicolumn{2}{c}{ Effective } & \multicolumn{2}{c}{ Peak } \\
\cline { 4 - 8 } & Trials & Riders & Mean & SD & Mean & SD \\
\hline A- Novice & 7 & 1 & 3.83 & 0.83 & 5.03 & 0.85 \\
B- Intermediate & 47 & 4 & 5.28 & 0.78 & 6.73 & 0.69 \\
C-Advanced & 78 & 6 & 6.79 & 0.68 & 8.82 & 0.63 \\
D - Expert & 25 & 2 & 8.03 & 0.49 & 9.82 & 0.50 \\
\hline
\end{tabular}

Figure 6 shows the distributions for the effective and peak deceleration values for the 157 emergency braking tests (both $\mathrm{TN}$ and TI) labeled by skill category of riders. The lines separating each category correspond to deceleration thresholds defined by the mean values plus and minus one standard deviation of the Table 2. 

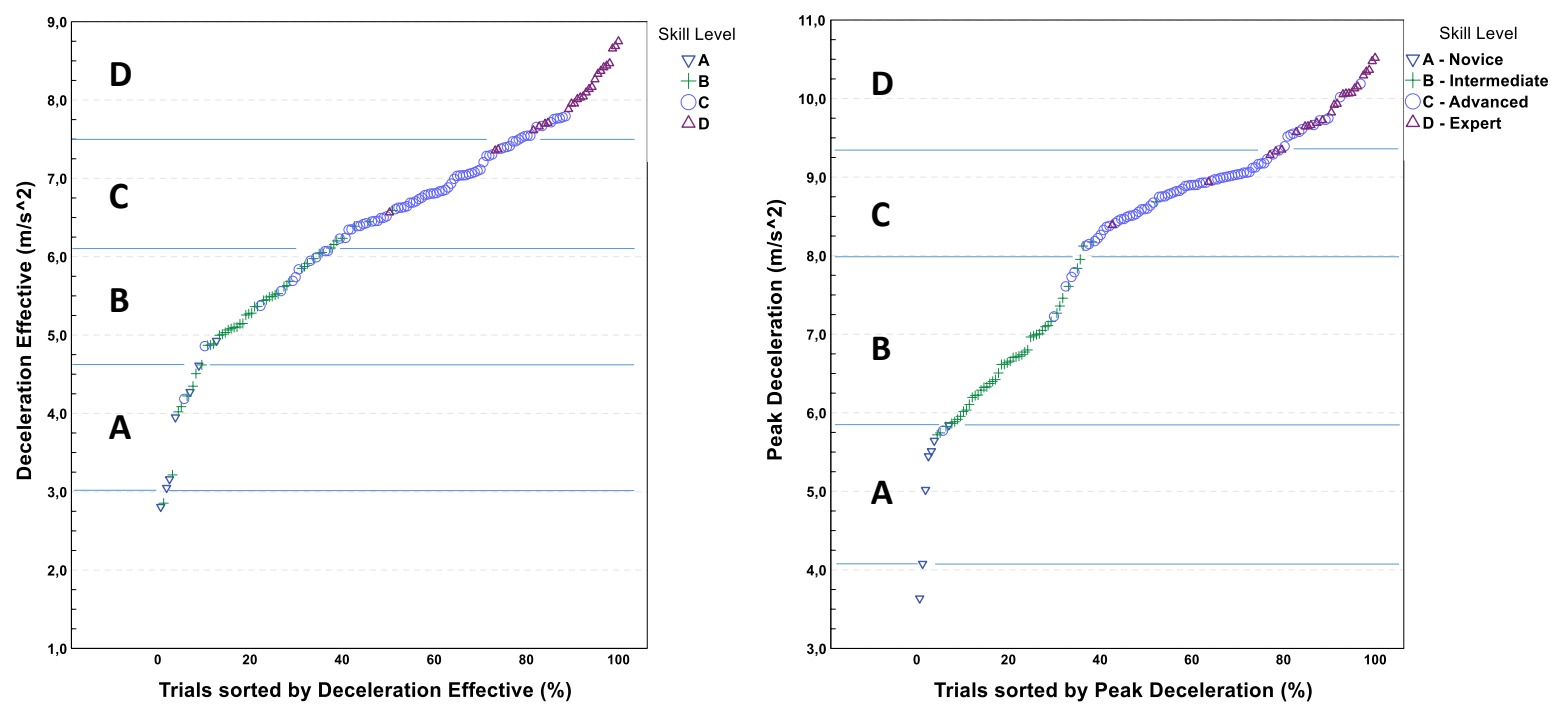

Figure 6. Distributions of effective and peak deceleration. On the $X$ axis, ' 0 ' represents the lowest deceleration value and ' 100 ' the highest deceleration from the 157 emergency trials.

As we can see in Table 2 and Figure 6, an effective deceleration of $7.5 \mathrm{~m} / \mathrm{s}^{2}$ represents the lower limit for the level ' $\mathrm{D}-$ Expert' ("mean of dec $_{\text {effective: }}$-1SD” of skill level 'D'). Interestingly, the distribution of the peak deceleration shows a clear 'gap' at $8.0 \mathrm{~m} / \mathrm{s}^{2}$ separating level 'C- Advanced' from level 'B- Intermediate'. This value may represent a threshold beyond which maintaining stability control of the PTW during hard deceleration requires notably greater skill.

\subsubsection{Effect of turn indicator on braking performance}

Results of the repeated measures ANOVA to test for effect of the presence of turn indicator (TN versus TI trials) on effective deceleration, showed that activation of the turn indicator during the emergency braking trials had a significant effect $\left(F(1,12)=8.38, p=.013, \eta_{p}{ }^{2}=.27\right)$. Deceleration values by subject (ID) are listed in Table 3 . Most riders exhibited a reduction of the performance (lower effective decelerations) when the driver used the indicator before turning (TI scenario). This did not appear to be the case for the two riders in category ' $\mathrm{D}$ - Expert'.

Table 3. Values of mean of effective deceleration $\left(\mathrm{m} / \mathrm{s}^{2}\right)$ per subject and level skill category

\begin{tabular}{|c|c|c|c|c|}
\hline & \multirow{2}{*}{$\begin{array}{c}\text { Overall } \\
\text { Mean (SD) }\end{array}$} & \multicolumn{2}{|c|}{$\begin{array}{ll}\text { TI } & \text { TN }\end{array}$} \\
\hline Level $^{*}$ & ID & & Mean (SD) & Mean (SD) \\
\hline A & SO2 & $3.83(0.83)$ & $3.24(0.49)$ & $4.60(0.33)$ \\
\hline \multirow{4}{*}{ B } & S08 & $4.77(0.79)$ & $4.32(1.00)$ & $5.17(0.17)$ \\
\hline & S09 & $5.15(0.65)$ & $5.12(0.83)$ & $5.18(0.52)$ \\
\hline & S06 & $5.54(0.63)$ & $5.15(0.66)$ & $5.88(0.45)$ \\
\hline & S12 & $5.68(0.73)$ & $5.51(0.95)$ & $5.81(0.52)$ \\
\hline \multirow{6}{*}{ C } & S11 & $6.65(0.23)$ & $6.60(0.20)$ & $6.71(0.26)$ \\
\hline & S10 & $6.55(0.62)$ & $6.40(0.74)$ & $6.72(0.42)$ \\
\hline & S01 & $6.65(0.65)$ & $6.59(0.47)$ & $6.72(0.86)$ \\
\hline & SO3 & $6.70(0.92)$ & 6.39 (1.29) & $6.96(0.38)$ \\
\hline & S07 & $7.14(0.75)$ & $7.54(0.16)$ & $6.74(0.90)$ \\
\hline & S13 & $7.11(0.61)$ & $7.05(0.45)$ & $7.16(0.76)$ \\
\hline \multirow[t]{2}{*}{ D } & S05 & $8.00(0.35)$ & $8.04(0.23)$ & $7.96(0.46)$ \\
\hline & SO4 & $8.05(0.61)$ & $7.92(0.75)$ & $8.16(0.49)$ \\
\hline
\end{tabular}

As Figure 7 shows, there is a large within-subject variability for most riders that may be consequence of a longitudinal learning effect during the test session. 


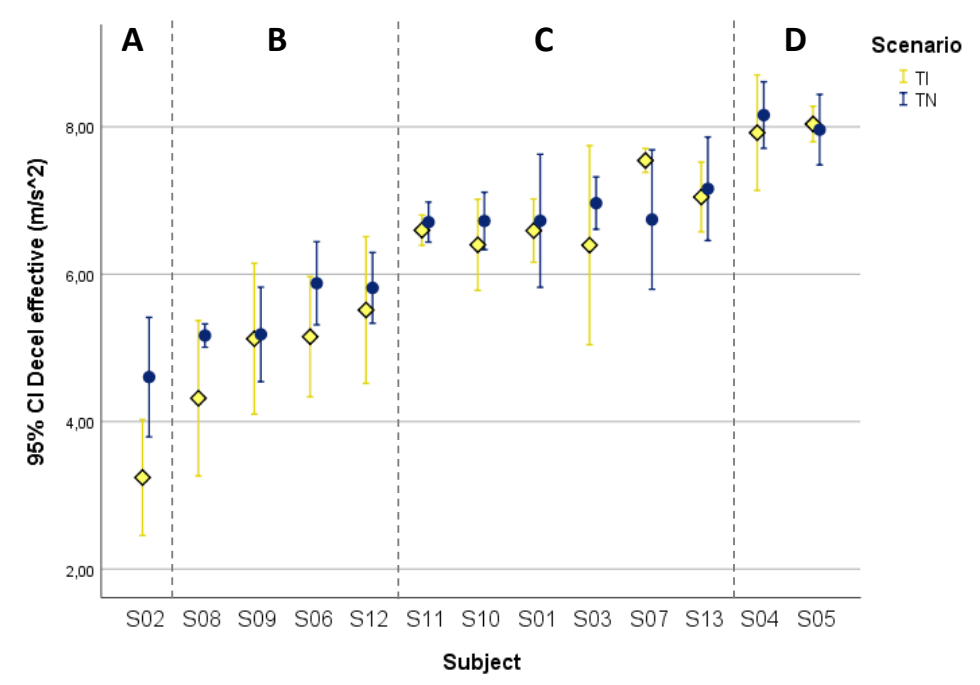

Figure 7. Mean and $95 \%$ Confidence Interval for effective deceleration braking

\subsection{Comparison of self-initiated Hard braking and Emergency braking test}

Data from hard braking tests were analysed for 11 participants, since participants identified as S01 and S02 were excluded due to incomplete data. A first descriptive analysis of effective braking deceleration $\left(\right.$ dec $\left._{\text {effective }}\right)$ shows little difference between the three last emergency braking trials in response to a perceived dynamic hazard and the three self-initiated hard braking trials (Figure $8 \mathrm{a}$ ). However, the boxplots of initial jerk from 0 to $4.5 \mathrm{~m} / \mathrm{s}^{2}$ (jerkini) from Figure $8 \mathrm{~b}$ suggests a characteristic trend across riders for higher initial jerk during emergency braking test. Mean values across all participants are presented in Table 4.

(a)

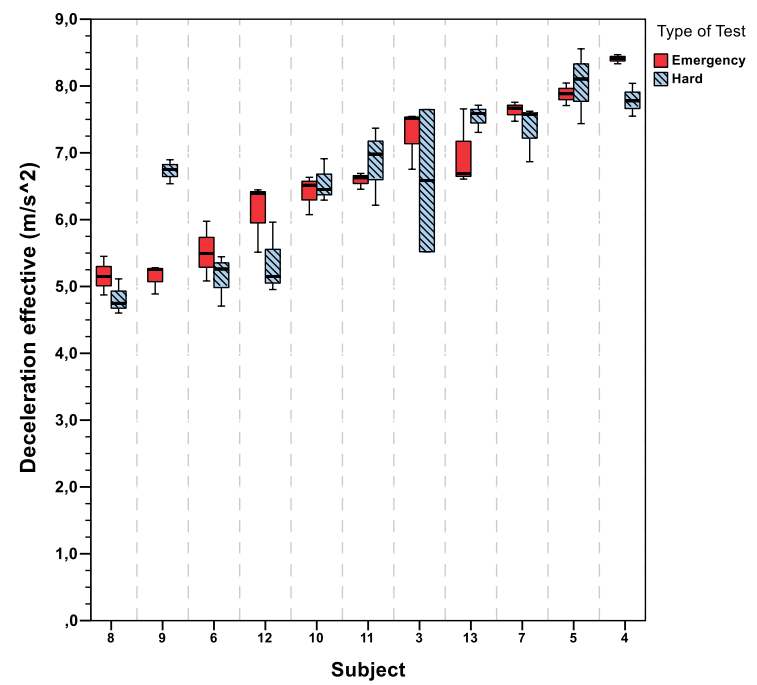

(b)

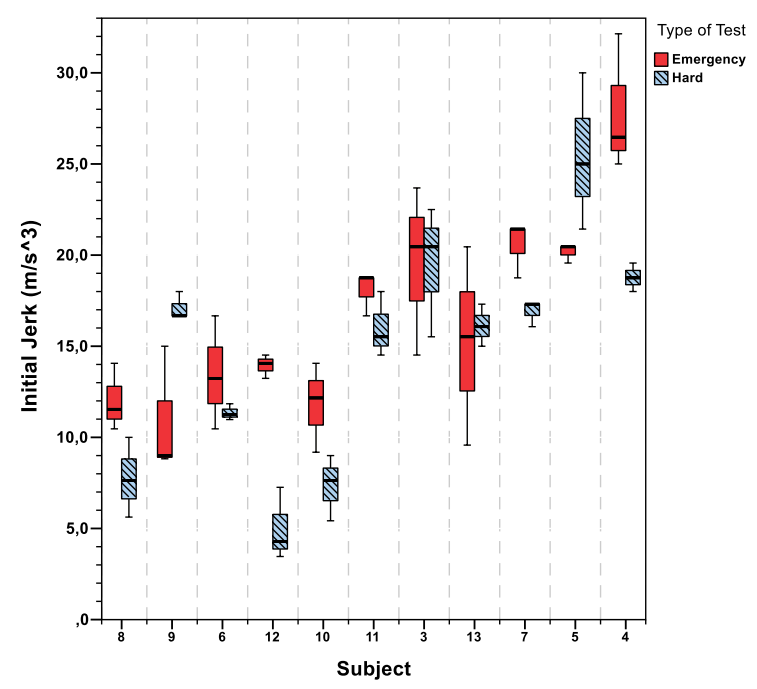

Figure 8. Box-plot for: a) effective deceleration $\operatorname{dec}_{\text {effective }}$; b) initial jerk $\left(j_{\text {jerk }}\right.$ ini). Subjects sorted by skill level

The results of the linear mixed model to assess the effect of the Type of Test in braking performance, confirmed that there was a significant difference in the scores between the emergency test and the hard braking test for jerk $k_{\text {ini }}(F(1,12.26)=5.02$; $p=.044$ ). Most riders exhibited higher initial jerk (mean difference $=2.0 \mathrm{~m} / \mathrm{s}^{3}$ ) in a task where the brakes had to be applied after the perception of a motion cue not predicted (car turning in a randomized design) than in a planned self-initiated braking task (see examples of Figure 9). The linear mixed-model with the best fit was a random slope and intercept model that considered for the random factor Rider their different baselines and different slopes. There were not significant differences between the two types of tests for $\operatorname{dec}_{\text {effective }}(F(1,54)=0.79, p=.379)$ and $\operatorname{dec}_{\text {peak }}(F(1,54)=2.93 ; p=.093)$. 
Table 4. Mean values of $\boldsymbol{d e c}_{\text {effective }}$ and jerk $\boldsymbol{k}_{\text {ini }}$ across participants

\begin{tabular}{lcccc}
\hline & \multicolumn{2}{c}{ dec $_{\text {effective }}\left(\mathbf{m} / \mathbf{s}^{\mathbf{2}}\right)$} & \multicolumn{2}{c}{ jerk $_{\text {ini }}\left(\mathbf{m} / \mathbf{s}^{\mathbf{3}}\right)$} \\
\hline ID & Emergency & Hard & Emergency & Hard \\
\hline S08 & 5.16 & 4.82 & 12.0 & 7.8 \\
S09 & 5.14 & 6.73 & 10.9 & 17.1 \\
S06 & 5.52 & 5.14 & 13.5 & 11.4 \\
S12 & 6.12 & 5.36 & 13.9 & 5.0 \\
S10 & 6.41 & 6.55 & 11.8 & 7.3 \\
S11 & 6.59 & 6.86 & 18.1 & 16.0 \\
S03 & 7.27 & 4.88 & 19.6 & 19.5 \\
S13 & 6.98 & 7.54 & 15.2 & 16.1 \\
S07 & 7.63 & 7.35 & 20.5 & 16.9 \\
S05 & 7.88 & 8.03 & 20.2 & 25.5 \\
S04 & 8.41 & 7.79 & 27.9 & 18.8 \\
\hline Total & 6.65 & 6.46 & 16.7 & 14.7 \\
\hline
\end{tabular}

(a)

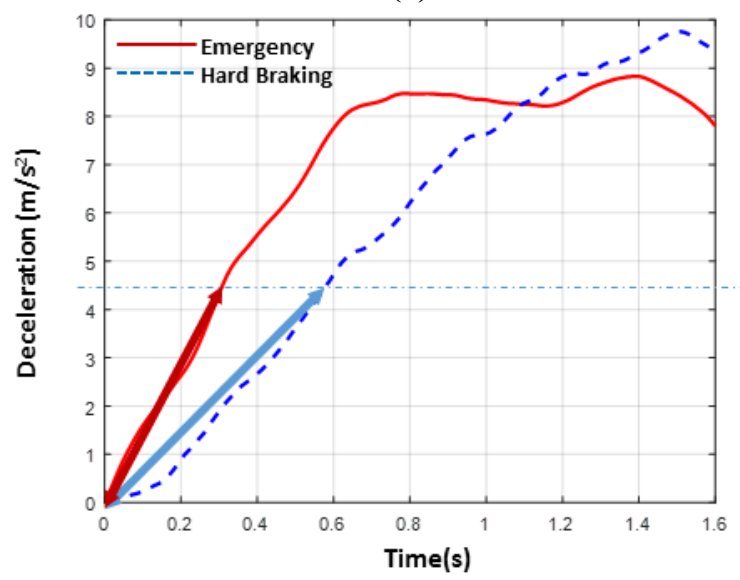

(b)

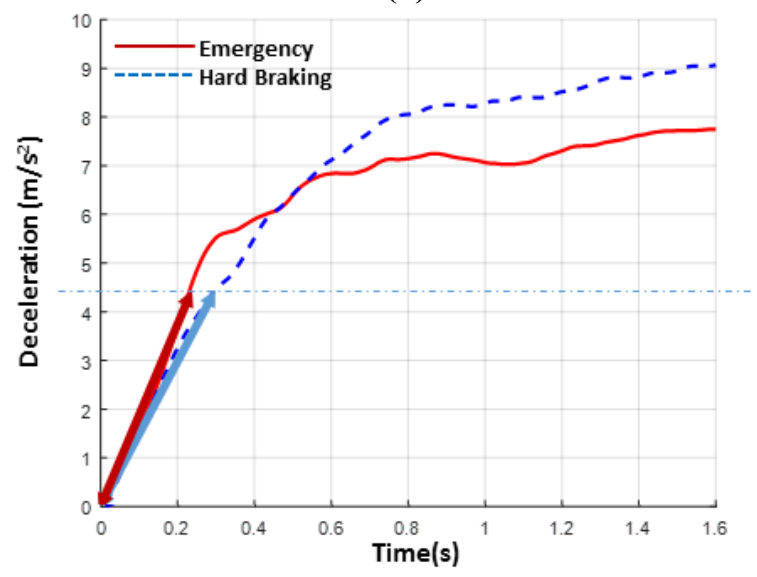

Figure 9. Comparison of jerkini between emergency braking tests and hard braking test for Subject S10 (a) and S11(b)

\subsection{Braking performance vs years of experience and skill self-assessment}

The demographic data collected by questionnaire prior to the experimental sessions were used to establish an 'a priori' classification of overall skill level. The self-assessment scores for expertise (overall skill) had four levels (Inexperienced, Experienced, Very experienced, Expert), as presented in Table 5. The scale used for the self-assessment scores for skills related to safety, hazard perception and braking was as follows: 1-poor, 2-room for improvement, 3-adequate, 4-good, 5-very good, 6-expert.

\begin{tabular}{c|c|c|c|l|c|c|c}
\hline \multicolumn{5}{|c|}{ Demographics } & \multicolumn{4}{c}{ Self-assessments } \\
\hline ID & Gender & Age & $\begin{array}{c}\text { Experience } \\
\text { (yrs.) }\end{array}$ & Overall Skill & Safety & $\begin{array}{c}\text { Hazard } \\
\text { Perception }\end{array}$ & Braking \\
\hline 1 & M & 27 & 10 & Very experienced & 2 & 4 & 3 \\
\hline 2 & F & 41 & 2 & Inexperienced & 2 & 2 & 1 \\
\hline 3 & M & 24 & 7 & Very experienced & 6 & 6 & 6 \\
\hline 4 & M & 26 & 10 & Very experienced & 6 & 6 & 5 \\
\hline 5 & M & 23 & 7 & Very experienced & 6 & 6 & 6 \\
\hline 6 & M & 47 & 31 & Expert & 2 & 4 & 3 \\
\hline 7 & M & 39 & 19 & Experienced & 4 & 5 & 4 \\
\hline 8 & F & 29 & 11 & Experienced & 2 & 4 & 2 \\
\hline 9 & M & 40 & 21 & Very experienced & 5 & 4 & 5 \\
\hline 10 & M & 24 & 8 & Experienced & 4 & 5 & 4 \\
\hline 11 & M & 24 & 6 & Expert & 5 & 5 & 4 \\
\hline 12 & M & 30 & 13 & Very Experienced & 4 & 5 & 4 \\
\hline 13 & M & 45 & NK & Experienced & 4 & 5 & 4 \\
\hline
\end{tabular}

Table 5. Summary of the demographic data and self-assessment by subject 
The correlations of mean effective deceleration with years of experience and with self-assessment of skills are shown in Table 6.

\begin{tabular}{|c|c|c|c|c|}
\hline & & \multicolumn{3}{|c|}{ Effective Deceleration } \\
\hline & & rho & $\mathrm{Cl}_{95}$ & $p$ \\
\hline \multicolumn{2}{|c|}{ Experience (years of riding) } & -0.16 & {$[-0.65,0.43]$} & .627 \\
\hline \multirow{4}{*}{$\begin{array}{c}\text { Self- } \\
\text { assessed }\end{array}$} & Overall Skill & 0.18 & {$[-0.37,0.66]$} & .564 \\
\hline & Safety & $0.66^{*}$ & {$[0.17,0.89]$} & .015 \\
\hline & Hazard Perception $^{* *}$ & $0.84^{* *}$ & {$[0.54,0.95]$} & .000 \\
\hline & Braking $^{*}$ & $0.66^{*}$ & {$[0.16,0.89]$} & .015 \\
\hline
\end{tabular}

Table 6. Spearman's rho tests correlation for effective deceleration and experience and self-assessment

Spearman's rho tests revealed that effective deceleration did not correlate with either number of years of experience riding or self-assessed overall skill. However, there was a strong positive correlation between effective deceleration and selfassessed hazard perception. There were medium positive correlations between mean average deceleration and both selfassessed braking and self-assessed safety.

\section{DISCUSSION}

The first objective of the study was to set skill levels in braking performance using objective measures. This was achieved by analysing effective and peak deceleration in a controlled real-world braking task with a Left Turn Across Path/Opposite Directions scenario. The results allowed definition of four levels of skill, with an effective deceleration of $7.5 \mathrm{~m} / \mathrm{s}^{2}$ as lower limit for expert riders and a peak deceleration of $8.0 \mathrm{~m} / \mathrm{s}^{2}$ as a threshold that differentiates expert and advanced riders from less skilled riders (intermediate and novice level). The mean of effective deceleration for experts and for advanced riders found in this study $\left(8.03 \mathrm{~m} / \mathrm{s}^{2}\right.$ and $6.79 \mathrm{~m} / \mathrm{s}^{2}$ respectively) are in agreement to the values found by Vavryn \& Winkelbauer (2004). Although the vehicles and test procedure differed (i.e. opponent vehicle as braking stimulus vs. self-timed braking), experienced riders from Vavryn and Winkelbauer's (2004) study achieved similar performance (7.8 $\mathrm{m} / \mathrm{s}^{2}$ braking on a PTW with ABS and $6.6 \mathrm{~m} / \mathrm{s}^{2}$ riding their own vehicles). The maximum deceleration we found for the two riders categorized as 'expert' based on the results of the post-hoc Tukey test (peak deceleration of $9.82 \mathrm{~m} / \mathrm{s}^{2}$ ) is also similar to the maximum deceleration rates $\left(10-11 \mathrm{~m} / \mathrm{s}^{2}\right)$ that Ecker et al. (2001) measured using an instrumented motorcycle. The variation in effective and peak deceleration across trials was also smaller for these riders. Both superior (i.e., higher deceleration rate) and more consistent (i.e., lower variability in deceleration rate) performance are representative of increased control of performance which is a synonymous with expertise (Ericsson, 1998; Magill \& Anderson, 2016).

The present study improves on the accuracy of certain measurements obtained in previous studies. Davoodi \& Hamid, (2013) and Vavryn \& Winkelbauer (2004), determined deceleration rates indirectly from measures of distance; instead, we used instantaneous deceleration sampled at $0.01 \mathrm{~s}$ intervals and then averaged across trials and participants. The nesting of samples in this manner gives a detailed picture of the time evolution of deceleration including peak deceleration within each emergency event and across situations. Anderson \& Baxter (2010) computed the constant higher deceleration values using the measure of the speed every 0.03-0.04 s with an external radar gun for moving objects, but the goal was to study the braking systems instead of rider performance and they used only one expert as test rider. Despite its effectiveness, our method still has some limitations. The speed measures from phonic wheels of our study did not consider the deformation caused by the load transfer from rear to front wheel, so some bias could be included due to the small variations of the radius of the wheels during the braking manoeuvre. Similarly, computing braking distances integrating the speed time series may be vulnerable to some data drift. 
Our study differs markedly from previous studies on braking due to the additional cognitive workload demanded of the riders, since they were required to perceive and predict the movements of an opponent vehicle, much closer to real traffic hazard than a static light signal. Indeed, we found that use of the indicator before turning (a distracting or misleading stimulus) had a negative effect on braking performance, particularly for the least skilled riders.

The scenario and procedure have been confirmed as a consistent method to identify the competencies of the riders in a demanding situation. The average TTI of 1.22 seconds in the proposed test scenario with the PTW traveling at a speed 50 $\mathrm{km} / \mathrm{h}$ can be considered highly demanding parameter for collision avoidance. To illustrate this more clearly, if the rider takes 0.2 seconds to initiate a response to avoid colliding with the turning car, the PTW must be decelerated at an average rate of $6.8 \mathrm{~m} / \mathrm{s}^{2}$, achievable only by high skilled riders. The characterization of different skill profiles based on deceleration parameters improves understanding of rider ability and limitations in the performance of emergency manoeuvres. In terms of design of new safety systems like autonomous braking, the results suggest that there is not one optimal deceleration pattern to be applied to all the riders, but riders with different skill levels will require different optimum deceleration curves. Same deceleration pattern in an autonomous braking system that may bring to loss control in less skilled riders, at the same time, may be undersized for highest skilled riders. The emergency task designed may be a useful test for classifying rider skills to support future customization of safety systems.

The second aim of this study was to determine whether the task procedure, which integrates moving hazard perception and response action, could be used to categorize riders in terms of skill in emergency braking. Comparing braking performance in the emergency scenario designed with a more standard hard braking task, this research showed that there were differences in the way of braking in the initial phase. The initial jerk of the riders after detecting an unpredicted hazard presence on the road (car crossing in front of the PTW) was different (mainly higher) than during planned hard braking test. Effective and peak deceleration, however, were not affected by the type of braking task. One of the main differences in the procedure of the two type of test is the onset of the brakes activation (planned vs unpredicted), that is directly related with the first phase of the braking action (characterized by the jerk $k_{\text {ini }}$ measurements). The differences found in our study are consistent with recent research on collision avoidance behaviour with car drivers (Markkula, Engström, Lodin, Bärgman, \& Victor, 2016; Wang, Zhu, Chen, \& Tremont, 2016). Markkula et al. (2016) indicated that drivers in crashes and near crashes braked with a larger jerk when the level of response urgency was higher. Similarly, Wang et al. (2016) showed that drivers in a simulator reached higher brake pressure gradient when the situation at brake onset was more critical (e.g., shorter distance to lead vehicle). In this context, assuming that in imminent crash scenarios riders must change their braking pattern, less skilled riders or with less automatism in emergency braking will most likely apply wrongly the force on the brakes if they have practiced braking only in completely different scenarios. Our findings suggest that the task designed in this study may induce participants to behave closer to the initial stage of a real emergency scenario than conventional braking tests. The fact that the rider is alerted and knows that the car is not going to cross the path may make the last phase of the emergency task defined more similar to a standard hard braking test.

The third objective of this study was to examine the relationship between self-assessed and objective measures of PTW riders' skill braking in a real-world situation. The results reveal that riders' actual emergency braking performance was not related to their years of riding experience or how skilled they believed they were overall. Rather, demonstrated skill in emergency braking was closely related to riders' self-assessment of their expertise in safe skills and the two component skills - perception of traffic hazards and braking. These results suggest that riders have good awareness of their skill in detecting and responding to an emergency, but this may bear little relationship to their years of riding experience or selfperceived overall skill - an important distinction given that years of experience is a reference commonly used for licensure. Thus, we caution that a rider's assessment of his/her own skill and safety in more global terms is not a reliable indicator 
of his/her ability to stop quickly in an emergency situation. One explanation for this result is that riders take into account multiple component skills when determining how skilled they believe they are, but that the skills on which riders base such overall assessment are not the critical skills involved in responding to emergency events. This finding has important implications for the prescription of rider training. While advanced riding courses are available, riders may not choose to participate in such courses if they believe that their existing level of skill and safety is already sufficient. Interestingly, riders' self-assessment for skill in visually detecting traffic hazards and braking was closely related to the deceleration rate achieved in response to the hazard posed by a car executing a left turn across their path (an LTAP/OD event). Critically, the strongest correlation was found between deceleration rate and self-assessed hazard perception $(r h o=0.84)$. In conclusion, it seems that deliberately practicing how to perceive an imminent collision and execute the appropriate avoidance manoeuvre may be valuable for crash risk reduction in emergency scenarios. In contrast, simply acquiring general riding experience may not be as effective.

The generalizability of these results is applicable to braking in straight-line conditions with dry pavement on a scooter PTW with standard brakes (no ABS). Consequently, acceleration values for other types of PTWs and in other road conditions may differ. Experienced motorcycle riders without experience riding scooters may have shown lower deceleration results in the tests than they would have on a motorcycle, considering the necessity to adapt to a different geometry and brake activation configuration (rear brake controlled by left hand instead of right foot), which could reduce automaticity and increase cognitive load of the task. It is also important to note that the two women from the sample (one self-defined as inexperienced and the other as intermediate experience rider) achieved the lowest deceleration rates. Further research should ascertain whether the muscle strength required in upper limbs, to operate the handlebar while counteracting the large inertial forces due to emergency braking, represents a constraint in women's braking performance regardless of their control skills.

As commented, a strength of this study is the realism of the emergency braking task involving an opponent vehicle and a degree of unpredictability as to its behavior. Nevertheless, an apparent limitation of the procedure lies in the fact that participants knew they would need to brake during the trials. Accordingly, although braking events were unpredicted alternating randomly braking events with the drive straight through condition, they were not completely unexpected. In our task, participants were instructed to respond to evidence of the car beginning to turn across their path using exclusively braking as manoeuvre. Thus, riders were not required to take decisions between various responses to avoid collision. Fewer action choices requires less cognitive processing to select and organize a motor response (Scott, 2016). Therefore, compared to real world riding, braking performance can be expected to be more 'ideal' during the experimental protocol defined in our study, additionally considering the lack of typical distractors associated with driving in the urban setting. Our sample of novice riders was limited to one, due to the difficulty of recruiting novice riders in Florence that meet all the study criteria. Specifically, since a significant proportion of Florentines begin riding at age 16 after obtaining A1 license (up to $125 \mathrm{cc}$ ) and upgrade to larger PTWs over 18 years old, it is very difficult to find new riders with a license permitting them to ride PTW with engines larger than $125 \mathrm{cc}$. Future studies are needed to address larger samples of both novices and very highly skilled riders.

The approach of this study goes beyond control skills assessment since central approach is performance in an emergency scenario. The test paradigm employed in this study addresses both the control skill for hard braking as well as the higher cognitive skill of hazard perception in traffic patterns. To improve at the real-world skill of emergency braking, these two components must be practiced in association, preserving the natural perception-action coupling, in order to develop the automatisms required for effective emergency braking. Previous authors have cautioned that training for improved skill may produce overconfidence (Ivers et al., 2016; Rowden \& Watson, 2008) or sensation-seeking behaviour, that does not 
translate to improved safety (Savolainen \& Mannering, 2007). By providing riders with objective feedback on such elements of their performance as disparity from target stopping distance, riders (including highly skilled riders) concern about their own limitation. Thus, tasks designed representing hazard scenarios and providing objective feedback can be used to promote defensive riding indirectly, highlighting the importance of the effect of speed in hazard perception and braking distance under the principle that handling an emergency is to prevent it in the first place. The results of this study, complemented with a study of the key indicators that characterizes highly skilled performance from the signals collected (e.g. brake pressure, ratio of deceleration, time to peak deceleration) may be used in a forthcoming phase of research involving design and testing of a training intervention. Furthermore, the data collected represents a rich dataset that will be used in ongoing studies to assess the interactions of perceptual, control and cognitive skills in emergency PTW manoeuvres. The findings of this study contribute to better understanding of the PTW riding behaviour in emergency scenarios and provide both methodological guidelines and data comparisons for future studies aiming to improve competencies in traffic safety.

\section{Acknowledgment}

This work was funded by the 7th Framework Program of the European Commission within the Marie Curie Research Training Network MOTORIST (MOTOrcycle Rider Integrated SafeTy, grant agreement n. 608092).

\section{REFERENCES}

ACEM. (2009). Motorcycle Accident In Depth Study.- In-depth investigations of accidents involving powered two wheelers. Final Report 2.0 (Vol. 32). Retrieved from http://www.maids-study.eu/pdf/MAIDS2.pdf

Altman, D. G., Machin, D., Bryant, T. N., \& Gardner, M. J. (2000). Statistics with confidence. BMJ Books. https://doi.org/10.4135/9781446218525

Anderson, B., \& Baxter, A. (2010). Comparison of Motorcycle Braking System Effectiveness. SAE Technical Paper, 172. https://doi.org/10.4271/2010-01-0072

António, P., \& Matos, M. (2008). An Evaluation of the Portuguese Moped Rider Training Programme. In L. Dorn (Ed.), Driver Behaviour and Training - Volume III (pp. 399-413). Hampshire - UK: Ashgate.

Attal, F., Boubezoul, A., Oukhellou, L., \& Espié, S. (2015). Powered two-wheeler riding pattern recognition using a machine-learning framework. IEEE Transactions on Intelligent Transportation Systems, 16(1), 475-487. https://doi.org/10.1109/TITS.2014.2346243

Aupetit, S., Riff, J., Buttelli, O., \& Espié, S. (2013). Naturalistic study of rider's behaviour in initial training in France: Evidence of limitations in the educational content. Accident Analysis and Prevention, 58, 206-217. https://doi.org/10.1016/j.aap.2012.09.036

Baldanzini, N., Huertas-Leyva, P., Savino, G., \& Pierini, M. (2016). Rider Behavioral Patterns in Braking Manoeuvres. Transportation Research Procedia, 14, 4374-4383. https://doi.org/10.1016/j.trpro.2016.05.359

Billheimer, J. W. (1998). Evaluation of California Motorcyclist Safety Program. Transportation Research Record 1640, $T R B$, (National Research Council, Washington, D.C.), 100-109.

Clarke, D. D., Ward, P., Bartle, C., \& Truman, W. (2007). The role of motorcyclist and other driver behaviour in two types of serious accident in the UK. Accident Analysis and Prevention, 39(5), 974-981. https://doi.org/10.1016/j.aap.2007.01.002

Cohen, J. (1988). Statistical power analysis for the behavioral sciences (2nd ed.). Lawrence Erlbaum Associates.

Collins, M., Mulvihill, C., \& Symmons, M. (2012). Differences in defensive riding skill and " RoadCraft" between novice and experienced motorcycle riders Unterschiede bei unerfahrenen und erfahrenen Motorradfahrern bezüglich ihrer Gefahrenbewältigungsstrategien im Straßenverkehr. In Forschungshefte Zweiradsicherheit, (15) 
(pp. 194-208).

Corno, M., Matteo, S., Tanelli, M., \& Fabbri, L. (2008). On optimal motorcycle braking. Control Engineering Practice, 16, 644-657. https://doi.org/10.1016/j.conengprac.2007.08.001

Cossalter, V., Lot, R., \& Maggio, F. (2004). On the braking behavior of motorcycles. SAE Paper 2004-32, 18(1). https://doi.org/10.4271/2004-32-0018

Daniello, Allison, Gabler, Hampton C, Mehta, \& Yusuf A. (2009). Effectiveness of Motorcycle Training and Licensing. Transportation Research Record: Journal of the Transportation Research Board, 2140, 206-213. https://doi.org/10.3141/2140-23

Davis, C. F. (1997). Evaluation of Community Traffic Safety Programs and Motorcycle Operator Training Programs: final report (No JHR97-255). Connecticut.

Davoodi, S. R., \& Hamid, H. (2013). Motorcyclist Braking Performance in Stopping Distance Situations. Journal of Transportation Engineering, (July), 130217204141006. https://doi.org/10.1061/(ASCE)TE.1943-5436.0000552

Dewar, A. R., Rupp, M. A., Gentzler, M. D., \& Mouloua, M. (2013). Improving motorcycle training programs: Suggestions and recommendations. Proceedings of the Human Factors and Ergonomics Society, (1995), 14851489. https://doi.org/10.1177/1541931213571331

Dinges, J., \& Hoover, T. (2018). A Comparison of Motorcycle Braking Performance with and without Anti-Lock Braking on Dry Surfaces. SAE International, 1-9. https://doi.org/10.4271/2018-01-0520

Dunn, A. L., Dorohoff, M., Bayan, F., Cornetto, A., Wahba, R., Chuma, M., ... Eiselstein, N. (2012). Analysis of Motorcycle Braking Performance and Associated Braking Marks. SAE Technical Paper. https://doi.org/10.4271/2012-01-0610

Ecker, H., Wassermann, J., Hauer, G., Ruspekhofer, R., \& Grill, M. (2001). Braking Deceleration of Motorcycle Riders. In International Motorcycle Safety Conference. Orlando, USA.

Elliott, M. A., Baughan, C. J., Broughton, J., Chinn, B., Grayson, G. B., Knowles, J., ... Simpson, H. (2003). Motorcycle safety: A scoping study. TRL Report 581. Transportation Research Laboratory. Crowthorne, England. Retrieved from http://strathprints.strath.ac.uk/20277/

Ericsson, K. A. (1998). The Scientific Study of Expert Levels of Performance: general implications for optimal learning and creativity. High Ability Studies, 9(1), 75-100. https://doi.org/10.1080/1359813980090106

Huertas-Leyva, P. (2018). Study of motorcyclist's behaviour during emergency braking in the perspective of training for safety. Ph.D. Thesis, University of Florence. Retrieved from http://hdl.handle.net/2158/1129272

Hurt, H. H. J., Ouellet, J., \& Thom, D. (1981). Motorcycle Accident Cause Factors and Identification of Countermeasures: Volume 1 Technical Report, January(Contract No. DOT HS-5-01160), 425 pgs.

Ivers, R. Q., Sakashita, C., Senserrick, T., Elkington, J., Lo, S., Boufous, S., \& De Rome, L. (2016). Does an on-road motorcycle coaching program reduce crashes in novice riders? A randomised control trial. Accident Analysis and Prevention, 86, 40-46. https://doi.org/10.1016/j.aap.2015.10.015

Jonah, B. A., Dawson, N. E., \& Bragg, B. W. E. (1982). Are formally trained motorcyclists safer? Accident Analysis and Prevention, 14(4), 247-255. https://doi.org/10.1016/0001-4575(82)90036-7

Kardamanidis, K., Martiniuk, A., Ivers, R., Stevenson, M., \& Thistlethwaite, K. (2010). Motorcycle rider training for the prevention of road traffic crashes. Cochrane Database of Systematic Reviews. https://doi.org/10.1002/14651858.CD005240.pub2

Magill, R., \& Anderson, D. (2016). Motor Learning and Control: Concepts and Applications (11 edition). New York: McGraw-Hill.

Markkula, G., Engström, J., Lodin, J., Bärgman, J., \& Victor, T. (2016). A farewell to brake reaction times? Kinematics-dependent brake response in naturalistic rear-end emergencies. Accident Analysis \& Prevention, 95 , 209-226.

Mortimer, R. G. (1988). A further evaluation of the motorcycle rider course. Journal of Safety Research, 19(4), 187196. https://doi.org/10.1016/0022-4375(88)90023-0 
OECD/ITF. (2015). Improving Safety for Motorcycle, Scooter and Moped Riders (OECD Publi). Paris. https://doi.org/10.1787/9789282107942-en

Penumaka, A. P., Savino, G., Baldanzini, N., \& Pierini, M. (2014). In-depth investigations of PTW-car accidents caused by human errors. Safety Science, 68, 212-221. https://doi.org/10.1016/j.ssci.2014.04.004

Prem, H. (1987). The emergency straight-path braking behaviour of skilled versus less-skilled motorcycle riders (No. 871228). SAE Technical Paper. Retrieved from https://www.sae.org/publications/technicalpapers/content/871228/

Rowden, P. J., \& Watson, B. C. (2008). Motorcycle rider training and perceptions of skill. Adelaide, Australia.

Savino, G., Giovannini, F., Baldanzini, N., Pierini, M., \& Rizzi, M. (2013). Assessing the potential benefits of the motorcycle autonomous emergency braking using detailed crash reconstructions. Traffic Injury Prevention, 14 S.(August 2013), S40-9. https://doi.org/10.1080/15389588.2013.803280

Savolainen, P., \& Mannering, F. (2007). Effectiveness of Motorcycle Training and Motorcyclists' Risk-Taking Behavior. Transportation Research Record, 2031(2031), 52-58. https://doi.org/http://dx.doi.org/10.3141/2031-07

Scott, S. H. (2016). A Functional Taxonomy of Bottom-Up Sensory Feedback Processing for Motor Actions. Trends in Neurosciences, 39(8), 512-526. https://doi.org/10.1016/j.tins.2016.06.001

Sporner, A., \& Kramlich, T. (2001). Motorcycle braking and its influence on severity of injury. In Proceedings of the 17th ESV Conference. (pp. 1-7). Retrieved from http://epi6.svmc.se/smc_filer/SMC centralt/Rapporter/ABSbromsar/Germany ABS.pdf

Vavryn, K., \& Winkelbauer, M. (2004). Braking Performance of Experienced and Novice Motorcycle Riders - Results of a Field Study. In 2004 International Conference on Transport and Trafficc Psychology. Nottingham, United Kingdom.

Wallace, P., Haworth, N., \& Regan, M. (2005). Best training methods for teaching hazard perception and responding by motorcyclists. Report no. 236. Monash University Accident Research Centre. Retrieved from https://www.monash.edu/_data/assets/pdf_file/0017/217214/muarc236.pdf

Wang, X., Zhu, M., Chen, M., \& Tremont, P. (2016). Drivers' rear end collision avoidance behaviors under different levels of situational urgency. Transportation Research Part C: Emerging Technologies, 71, 419-433. https://doi.org/10.1016/j.trc.2016.08.014 